\title{
Unilateral Hyperhidrosis and Contralateral Horner's Syndrome Due to Syringomyelia
}

\author{
Siringomiyeliye Bağlı Unilateral Hiperhidrosis ve Kontralateral Horner Sendromu
}

Keywords: Syringomyelia, unilateral hyperhidrosis, Horner's syndrome

Anahtar Kelimeler: Siringomiyeli, unilateral hiperhidrosis, Horner sendromu

\section{Dear editor,}

A 40-year-old male patient was admitted to the neurology department due to extreme sweating on the left side of his face and body. His complaint had started four years ago and progressed slowly. Last year, he also noticed slight drooping of his right eyelid. Sixteen years ago, he had developed a headache accompanied by left upper extremity weakness and hypoesthesia. Radiological workup demonstrated a syrinx involving the C5-T9 segments of the spinal cord (Figure 1A). He underwent a syringo-pleural shunt operation at the level of T6-T7 segments (Figure 1B). His complaints largely subsided. He did not have hyperhidrosis then. Personal history revealed Erb-Duchenne palsy involving his left upper extremity. Neurologic examination demonstrated right sided Horner's syndrome, mild weakness in the left upper extremity (MRC grade 4/5) and generalized hyporeflexia. Patient photographs and starchiodine test demonstrated increased sweating on the left side of his face and body (Figure 2). Apraclonidine test led to dilatation of the constricted pupil with elevation of the eyelid on the right side thus confirming the presence of Horner's syndrome. Cervico-thoracic spinal magnetic resonance imaging (MRI) showed syringomyelia between $\mathrm{C} 2$ and $\mathrm{T} 8$, predominantly on the right side and more cranially (Figure 3).

To the best of our knowledge, only one case with bilateral hyperhidrosis and unilateral Horner's syndrome due to syringomyelia (extending between C4-T8) was reported in the literature (1). Syringomyelia may be either idiopathic or due to spinal cord injury. It has been suggested that one of the possible mechanisms may be birth trauma leading to hematomyelia or arachnoid scarring. Our patient had Erb-Duchenne palsy suggesting that he may have had perinatal spinal injury. In some
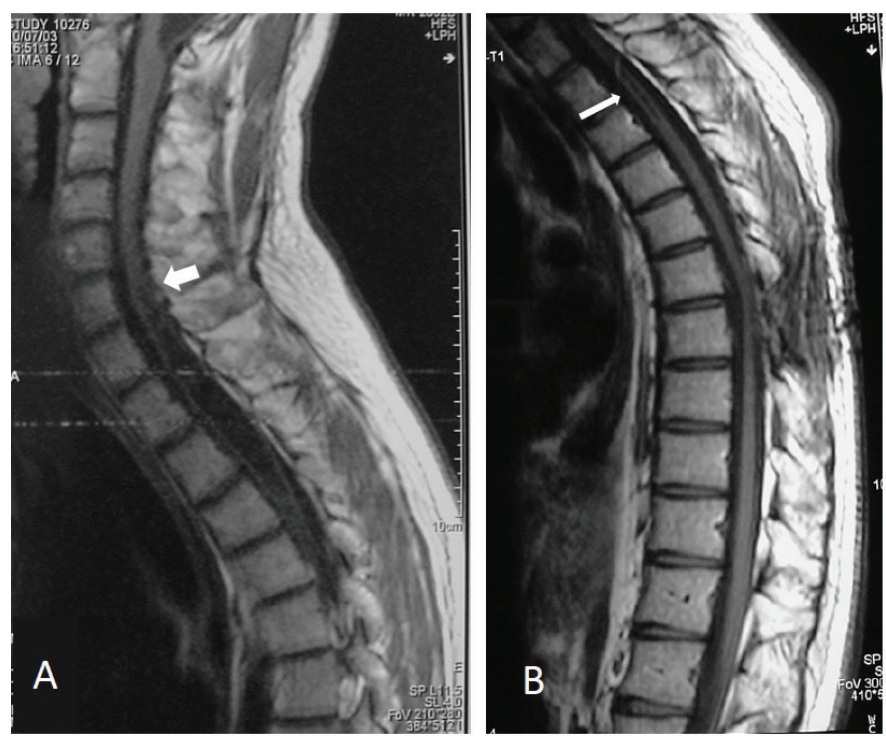

Figure 1. T1W sagittal MR imaging section of the spinal cord at cervical-upper thoracic level demonstrates the upper border of the syrinx (thick white arrow) (A); eight months later, postoperative MR imaging of the thoracic level indicates significant resolution of the syrinx cavity (thin white arrow) (B)

MR: Magnetic resonance

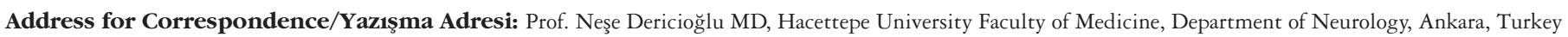
Phone: +90 3123051809 E-mail: nesedr@hacettepe.edu.tr ORCID: orcid.org/0000-0003-2465-3017

Received/Geliş Tarihi: 26.02.2021 Accepted/Kabul Tarihi: 22.12.2021

${ }^{\circ}$ Copyright 2022 by Turkish Neurological Society

Turkish Journal of Neurology published by Galenos Publishing House. 
patients, syringomyelia is known to present years after injury, usually with pain, spasticity and motor deficits. Our patient's complaints remitted after surgery. However, 12 years later he presented with hyperhidrosis affecting the left side of his face and body, accompanied by right sided Horner's syndrome. De novo development of these symptoms was accompanied by progression of the syrinx cavity cranially, as was demonstrated by extension of the upper limit of the syrinx to C2 level on cervical MRI. The occurrence of right sided Horner's syndrome and left sided hyperhidrosis may perhaps be explained by the asymmetric appearance of the syrinx cavity in the upper cervical segments.

Sweat glands are innervated by the sympathetic nervous system, the fibers of which are thought to originate in the cortex
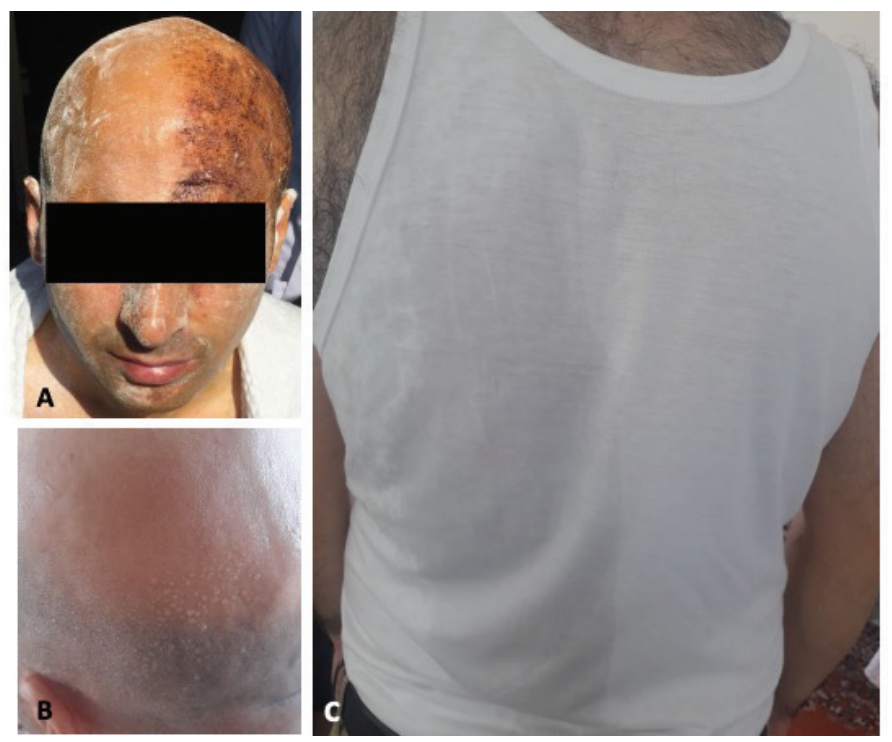

Figure 2. Starch-iodine test demonstrates involvement of the left side of the patient's face (more prominent on the forehead) (A); sweat droplets can be seen at the back of the head on the left (B); increased sweating on the left side of the patient's back is noticeable $(\mathrm{C})$

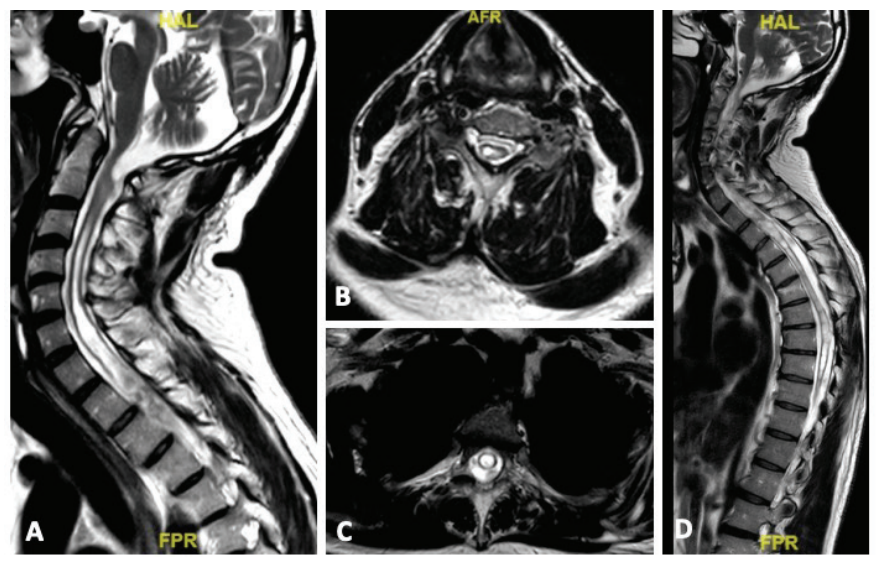

Figure 3. Sagittal T2W spinal MR imaging demonstrates the syrinx cavity at the cervical level (A); the syrinx is located asymmetrically and involves the right side of the cord between $\mathrm{C} 2-\mathrm{C} 5$ ( $\mathrm{B}$, level $\mathrm{C} 5$ ), more caudally it is quite symmetric (C, level T3); the lower border of the syrinx can be seen at the T8 level (D)

MR: Magnetic resonance (perhaps operculum), traverse the ipsilateral hypothalamus and brain stem, cross at the spinal level and then make terminal connections with the contralateral sympathetic sudomotor neurons at segments T1-L2. Lesions of the cerebral hemispheres, hypothalamus, pons, medulla or cervical spinal cord may result in contralateral hyperhidrosis. Several mechanisms have been proposed: 1- Crossed inhibitory hypothalamo-spinal sympathetic pathway, which controls sweating of the contralateral face and body (2); 2- Increased stimulation of the ipsilateral sympathetic preganglionic neurons (3); 3-Compensatory hyperhidrosis on the contralateral side of the body (4). Our findings overall may be in favor of the presence of a crossed inhibitory input to sympathetic ganglia.

\section{Ethics}

Informed Consent: Written consent was obtained.

Peer-review: Externally peer-reviewed.

\section{Authorship Contributions}

Surgical and Medical Practices: S.P., Concept: N.D., Design: N.D., Data Collection or Processing: N.D., Analysis or Interpretation: N.D., S.P., Literature Search: N.D., Writing: N.D.

Conflict of Interest: No conflict of interest was declared by the authors.

Financial Disclosure: The authors declared that this study received no financial support.

\section{References}

1. Glasauer FE, Czyrny JJ. Hyperhidrosis as the presenting symptom in posttraumatic syringomyelia. Paraplegia 1994;32:423-429.

2. Labar DR, Mohr JP, Nichols FT 3rd, Tatemichi TK. Unilateral hyperhidrosis after cerebral infarction. Neurology 1988;38:1679-1682.

3. Sudou K, Tashiro K. Segmental hyperhidrosis in syringomyelia with Chiari malformation. J Neurol 1993;240:75-78.

4. Stancanelli C, Mazzeo A, Gentile L, Vita G. Unilateral hyperhidrosis as persistently isolated feature of syringomyelia and Arnold Chiari type 1. Neurol Sci 2018;39:1607-1608. 